\title{
Impact of the diabetes Canada guideline dissemination strategy on dispensed vascular protective medications for older patients in Ontario, Canada: a linked EMR and administrative data study
}

Michelle Greiver ${ }^{1,2,3,4^{*}}$, Sumeet Kalia ${ }^{2}$, Rahim Moineddin ${ }^{2,3}$, Simon Chen ${ }^{3}$, Raquel Duchen ${ }^{3}$ and Alanna Rigobon ${ }^{5}$

\begin{abstract}
Background: The 2013 Diabetes Canada guidelines recommended routinely using vascular protective medications for most patients with diabetes. These medications included statins and angiotensin-converting enzyme inhibitors (ACEls) or angiotensin receptor blockers (ARBs). Antiplatelet agents were only recommended for secondary prevention of cardiovascular disease. Using Electronic Medical Record (EMR) data, we previously found that guideline dissemination efforts were not associated with an increase in the rate of primary care prescriptions of these medications. However, this needs confirmation: patients can receive prescriptions from different sources including specialists and they may not always fill these prescriptions. Using both EMR and administrative health data, we examined whether guideline dissemination impacted the dispensing of vascular protective medications to patients.
\end{abstract}

Methods: The study population included patients with diabetes aged 66 or over in Ontario, Canada. We created two cohorts using two different approaches: an Electronic Medical Record (EMR) algorithm for diabetes using linked EMRadministrative data and an administrative algorithm using population level administrative data. We examined data from January 2010 to December 2016. Patients with diabetes were deemed to be likely taking a medication (or covered) during a quarter if the daily amount for a dispensed medication would last for at least $75 \%$ of days in any given quarter. An interrupted time series analysis was used to assess the proportion of patients covered by each medication class. Proton pump inhibitors (PPIs) were used as a reference.

(Continued on next page)

\footnotetext{
* Correspondence: m.greiver@utoronto.ca

'Gordon F. Cheesbrough Chair in Family and Community Medicine Research,

North York General Hospital, 4001 Leslie Street, LE-140, Toronto, Ontario M2K

1E1, Canada

${ }^{2}$ Department of Family and Community Medicine, Faculty of Medicine,

University of Toronto, 500 University Avenue, Toronto, Ontario M5G 1V7,

Canada

Full list of author information is available at the end of the article
}

C C The Author(s). 2020 Open Access This article is licensed under a Creative Commons Attribution 4.0 International License, which permits use, sharing, adaptation, distribution and reproduction in any medium or format, as long as you give appropriate credit to the original author(s) and the source, provide a link to the Creative Commons licence, and indicate if changes were made. The images or other third party material in this article are included in the article's Creative Commons licence, unless indicated otherwise in a credit line to the material. If material is not included in the article's Creative Commons licence and your intended use is not permitted by statutory regulation or exceeds the permitted use, you will need to obtain permission directly from the copyright holder. To view a copy of this licence, visit http://creativecommons.org/licenses/by/4.0/ The Creative Commons Public Domain Dedication waiver (http://creativecommons.org/publicdomain/zero/1.0/) applies to the data made available in this article, unless otherwise stated in a credit line to the data. 
(Continued from previous page)

Results: There was no increase in the rate of change for medication coverage following guideline release in either the EMR or the administrative diabetes cohorts. For statins, the change in trend was $-0.03, p=0.7$ (EMR) and $-0.12, p=$ 0.04 (administrative). For ACEl/ARBs, this was $0.03, p=0.6$ (EMR) and $0, p=1$ (administrative). For antiplatelets, this was $0.001, P=.97$ (EMR) and $-0.03, p=0.03$ (administrative). The comparator PPI was $-0.07, p=0.4(E M R)$ and $-0.11, p=$ 0.002 (administrative).

Conclusions: Using both EMR and administrative health data, we confirmed that the Diabetes Canada 2013 guideline dissemination strategy did not lead to an increased rate of coverage for vascular protective medications. Alternative strategies are needed to effect change in practice.

Keywords: Guideline adherence, Drug utilization, Diabetes mellitus, Primary health care, Electronic health records, Cardiovascular diseases/prevention \& control

\section{Background}

Diabetes is a highly prevalent chronic condition, associated with a significantly elevated risk of adverse cardiovascular outcomes, including coronary heart disease and strokes [1]. Effective cardiovascular risk reduction with vascular protective medications for appropriate patients, including statins, angiotensin-converting enzyme inhibitors (ACEIs) or angiotensin receptor blockers (ARBs) and antiplatelet agents is an essential component of diabetes management [2].

To improve the uptake of vascular protective medications, Diabetes Canada issued simplified guidelines in 2013. The 2008 guidelines recommended stratifying patients into risk categories. Patients at high risk should receive one of more of ACEIs or ARBs, statins or possibly ASA [3]. The 2013 guidelines simplified this and no longer require risk stratification. Therefore, the complexity of decisions was reduced as recommendations to start a vascular protective medication were largely based on patient age. The guidelines recommended statins for patients age 40 or over and ACEIs/ARBs for patients age 55 or over. Antiplatelet agents were no longer recommended for the primary prevention of cardiovascular disease but continue to be recommended for secondary prevention [2]. These recommendations were disseminated and implemented nationwide using the Knowledge-to-Action Framework [4]. Interventions including in-person lecture series, conferences, webinars, web-based professional and patient resources such as flow sheets, electronic point of care decision support, a mobile application, and electronic medical record (EMR) templates were rolled out over 24 months starting April 2013 [5]. The recommendations for vascular protection continue to be endorsed through the most recently released 2018 guidelines [6].

We recently examined the uptake of vascular protective medications in Canada following the release of the 2013 Diabetes Canada guidelines, using primary care EMR data from the Canadian Primary Care Sentinel Surveillance Network (CPCSSN), a pan-Canadian EMR-based surveillance system. Primary care providers participating in CPCSSN consent to contribute de-identified EMR data to regional network repositories; patients can opt-out. Data from all participating networks are extracted and processed every 6 months and aggregated in a single central database [7].

We found no improvements in the trend for rates of prescriptions [8]. While the EMR provides information on whether a patient was given a prescription by their primary care provider, it may not provide complete information on whether a patient has filled the prescription or is likely taking the medication (coverage rate). Prescriptions may be received from other providers as patients with diabetes may see both a family physician and an endocrinologist for care. As well, data on the duration of each prescription may be incompletely captured: a medication may be prescribed with several refills that may not be completely captured due to the structure of the EMR. Our previous guideline evaluation used a lag-lead approach to account for such variations in refill protocol and prescription procedures among family physicians [8]. Validating our results using different sources of information under different assumptions is important.

Health administrative databases and clinical data derived from EMRs provide complementary information, and can lead to more complete understanding of patients' care trajectories [9-11]. Diabetes case definitions based on EMR data have higher sensitivity than those based on administrative data [12, 13]. When validated against chart audits, the sensitivity and specificity for diabetes using CPCSSN data are 95.6 and 97.1\% [12]. A widely used, validated Canadian case definition using administrative data has a sensitivity of $86 \%$ and a specificity of $97 \%$ [14]. EMR data contains information that may not be present in administrative data, including the presence of a diagnosis for the disease in patients' summary health profiles [13, 15]. Health administrative databases are population based and provide information from sources not captured in EMRs, including hospital visits and specialist encounters [16].

We are now therefore validating our results using data from ICES (formerly the Institute for Clinical Evaluative 
Sciences), a prescribed entity under Ontario's privacy legislation authorized to collect and use health care data for the purposes of health system analysis, evaluation and decision support [17]. Our research questions were: did the 2013 Diabetes Canada guidelines influence the coverage of vascular protective medications in patients with diabetes? Was the change in coverage rates obtained using administrative data and linked administrative-EMR data similar to the change in prescription rates obtained using only primary care clinical EMR data? Was a population-based trend in coverage rates similar to our earlier results?

\section{Methods}

This was a retrospective cohort study; we used the Strengthening the Reporting of Observational Studies in Epidemiology guidelines to report the study [18].

\section{Setting and participants}

This study was conducted using data from Ontario, Canada. Ontario's health care system includes universal, tax-funded coverage for all medically necessary physician services and laboratory tests, with no patient copayment. About $75 \%$ of Ontario's population is formally registered or enrolled in primary care; each patient is attached to the practice of a family physician. $75 \%$ of family physicians practicing comprehensive care use a patient enrollment model. $25 \%$ of physicians in patient enrollment models practice in inter-professional Family Health Teams [19].

Two different validated algorithms to define two cohorts of patients living with diabetes were used to examine our data. The first used the CPCSSN (EMR derived) algorithm [20] and the second used the Ontario Diabetes Database (ODD), derived using an administrative data algorithm [14].

\section{EMR cohort}

We used EMR data from the Ontario sites of CPCSSN, extracted up to the end of 2014 and linked at ICES [21]. The four sites included were: Toronto and surroundings, eastern Ontario, Hamilton and London. The CPCSSN algorithm for diabetes [12] was used to identify patients with diabetes in that dataset.

Linked CPCSSN-ICES data from January 1st, 2010 to December 31st 2016 were included. We retrieved data on patients that were present in the CPCSSN dataset, had a valid Ontario health card number, were enrolled or virtually enrolled to a primary care physician and were age 66 or more at the beginning of each quarter of interest. Patients were enrolled in the cohort during or after the quarter containing their first patient-physician encounter as recorded in CPCSSN, if they met the
CPCSSN definitions for diabetes at any time prior to each quarter of interest.

\section{Administrative cohort}

We replicated the study using Ontario population based administrative data. Ontario has a population based publicly funded healthcare system; a unique health care number (the Ontario Health Insurance Plan or OHIP) identifies each patient. We used a validated administrative definition for diabetes, the ODD, which is a population-based registry at ICES [14]. The ODD validated algorithm labels cases as diabetes if there are two physician billing claims for diabetes (ICD9 code 250) or one hospitalization discharge record with a diagnostic code of diabetes within 2 years [14]. Patients likely to have gestational diabetes are excluded by not counting billing claims or hospitalizations that appeared 120 days before or 180 days after a hospital record with a diagnosis of pregnancy care or delivery [14].

Similar to the EMR cohort, ICES data from January 1st, 2010 to December 31st 2016 were included. We retrieved data on patients that had a valid Ontario health card number and were age 66 or more at the beginning of each quarter of interest. Patients were enrolled in the cohort if they met the ODD definitions for diabetes at any time prior to each quarter of interest.

Patients were censored from the cohort during the quarter in which they met at least one of the following conditions 1) deceased; 2) last encounter with the healthcare system prior to study end date; 3 ) loss of eligibility for Ontario's publicly funded health insurance plan, OHIP; 4) No longer enrolled or virtually enrolled with a primary care physician.

\section{Variables}

The outcome of interest was prescription coverage rates as an indication of whether a patient with diabetes was likely taking an appropriate cardiovascular protective medication in each quarter of interest as per Diabetes Canada guidelines between January 1, 2010 and December 31, 2016. Proton pump inhibitors (PPIs) were used as a comparator for secular trends.

The medications of interest were: 1) Statins; 2) ACE Inhibitors; 3) ARBs; 4) Antiplatelets (only for those with no cardiovascular disease); 5) PPIs.

\section{Data sources}

ICES holds databases on OHIP eligibility, publicly funded medications, and encounters with the health care system such as inpatient and outpatient visits. These datasets were linked using unique encoded identifiers and analyzed at ICES. All patients age 65 or more and covered by OHIP are eligible for publicly funded medication coverage through the Ontario Drug Benefit 
Table 1 Patient characteristics for the first quarter of each year of interest, EMR cohort

\begin{tabular}{|c|c|c|c|c|c|c|c|}
\hline & 2010Q1 & 2011Q1 & 2012Q1 & 2013Q1 & 2014Q1 & 2015Q1 & 2016Q1 \\
\hline TOTAL & $N=4385$ & $N=5342$ & $N=6071$ & $N=6819$ & $N=7330$ & $N=7424$ & $N=7363$ \\
\hline Flagged in ODD & $4258(97.1 \%)$ & $5167(96.7 \%)$ & $5839(96.2 \%)$ & $6467(94.8 \%)$ & 6914 (94.3\%) & $6986(94.1 \%)$ & $6933(94.2 \%)$ \\
\hline Have no encounter date* & $624(14.2 \%)$ & $637(11.9 \%)$ & $631(10.4 \%)$ & $653(9.6 \%)$ & 687 (9.4\%) & $673(9.1 \%)$ & $662(9.0 \%)$ \\
\hline \multicolumn{8}{|l|}{ Age } \\
\hline Mean \pm SD & $75.83 \pm 6.83$ & $75.78 \pm 6.91$ & $75.88 \pm 6.97$ & $75.83 \pm 7.08$ & $75.77 \pm 7.22$ & $75.96 \pm 7.29$ & $76.08 \pm 7.33$ \\
\hline Median (IQR) & $75(70-81)$ & $75(70-81)$ & $75(70-81)$ & $75(70-81)$ & $75(70-81)$ & $75(70-81)$ & $75(70-81)$ \\
\hline \multicolumn{8}{|l|}{ Sex } \\
\hline Female & $2216(50.5 \%)$ & $2694(50.4 \%)$ & $3034(50.0 \%)$ & $3459(50.7 \%)$ & 3733 (50.9\%) & 3793 (51.1\%) & $3768(51.2 \%)$ \\
\hline Male & 2169 (49.5\%) & $2648(49.6 \%)$ & $3037(50.0 \%)$ & $3360(49.3 \%)$ & $3597(49.1 \%)$ & 3631 (48.9\%) & $3595(48.8 \%)$ \\
\hline \multicolumn{8}{|l|}{ Income quintile } \\
\hline Q1 (lowest) & $811(18.5 \%)$ & 955 (17.9\%) & $1072(17.7 \%)$ & $1209(17.7 \%)$ & $1315(17.9 \%)$ & $1331(17.9 \%)$ & $1319(17.9 \%)$ \\
\hline Q2 & 809 (18.4\%) & $986(18.5 \%)$ & $1131(18.6 \%)$ & $1295(19.0 \%)$ & $1387(18.9 \%)$ & $1401(18.9 \%)$ & $1423(19.3 \%)$ \\
\hline Q3 & 860 (19.6\%) & 1064 (19.9\%) & 1179 (19.4\%) & 1361 (20.0\%) & $1453(19.8 \%)$ & $1458(19.6 \%)$ & 1435 (19.5\%) \\
\hline Q4 & 934 (21.3\%) & $1130(21.2 \%)$ & $1289(21.2 \%)$ & $1410(20.7 \%)$ & 1532 (20.9\%) & 1550 (20.9\%) & $1531(20.8 \%)$ \\
\hline Q5 (highest) & 970 (22.1\%) & 1203 (22.5\%) & 1391 (22.9\%) & 1531 (22.5\%) & 1633 (22.3\%) & 1672 (22.5\%) & $1642(22.3 \%)$ \\
\hline Rural & 1026 (23.4\%) & $1270(23.8 \%)$ & $1435(23.6 \%)$ & $1575(23.1 \%)$ & 1680 (22.9\%) & 1708 (23.0\%) & $1687(22.9 \%)$ \\
\hline \multicolumn{8}{|l|}{ ADG } \\
\hline Mean \pm SD & $7.54 \pm 3.86$ & $7.63 \pm 3.83$ & $7.70 \pm 3.85$ & $7.79 \pm 3.87$ & $7.71 \pm 3.88$ & $7.68 \pm 3.93$ & $7.71 \pm 3.92$ \\
\hline Median (IQR) & $7(5-10)$ & $7(5-10)$ & $7(5-10)$ & $7(5-10)$ & $7(5-10)$ & $7(5-10)$ & $7(5-10)$ \\
\hline \multicolumn{8}{|l|}{ RUB } \\
\hline Mean \pm SD & $3.65 \pm 0.89$ & $3.66 \pm 0.90$ & $3.66 \pm 0.91$ & $3.68 \pm 0.90$ & $3.67 \pm 0.90$ & $3.67 \pm 0.91$ & $3.66 \pm 0.92$ \\
\hline Median (IQR) & $3(3-4)$ & $3(3-4)$ & $3(3-4)$ & $3(3-4)$ & $3(3-4)$ & $3(3-4)$ & $3(3-4)$ \\
\hline OMID (AMI) & $369(8.4 \%)$ & 431 (8.1\%) & $505(8.3 \%)$ & 549 (8.1\%) & 577 (7.9\%) & $588(7.9 \%)$ & $582(7.9 \%)$ \\
\hline \multicolumn{8}{|l|}{ Enrollment status } \\
\hline Enrolled & 4142 (94.5\%) & $5083(95.2 \%)$ & $5774(95.1 \%)$ & 6469 (94.9\%) & 6958 (94.9\%) & 7046 (94.9\%) & $6952(94.4 \%)$ \\
\hline Virtually enrolled & $243(5.5 \%)$ & $259(4.8 \%)$ & 297 (4.9\%) & $350(5.1 \%)$ & $372(5.1 \%)$ & $378(5.1 \%)$ & 411 (5.6\%) \\
\hline CVD & $2856(65.1 \%)$ & 3695 (69.2\%) & $4257(70.1 \%)$ & 4901 (71.9\%) & 5389 (73.5\%) & $5449(73.4 \%)$ & $5386(73.1 \%)$ \\
\hline $\mathrm{CHF}$ & 628 (14.3\%) & 820 (15.4\%) & $901(14.8 \%)$ & 985 (14.4\%) & 1054 (14.4\%) & 1091 (14.7\%) & 1069 (14.5\%) \\
\hline OMID (AMI) & $369(8.4 \%)$ & 431 (8.1\%) & $505(8.3 \%)$ & $549(8.1 \%)$ & 577 (7.9\%) & $588(7.9 \%)$ & $582(7.9 \%)$ \\
\hline HTN & 3610 (82.3\%) & 4398 (82.3\%) & 5009 (82.5\%) & $5635(82.6 \%)$ & $6039(82.4 \%)$ & $6124(82.5 \%)$ & $6089(82.7 \%)$ \\
\hline
\end{tabular}

ODD: Ontario Diabetes Database; SD: standard deviation; IQR: interquartile range; ADG: adjusted diagnostic groups; RUB: resource utilization band; OMID: Ontario myocardial infarct dataset; AMI: acute myocardial infarct; CVD: cardiovascular disease; CHF: congestive heart failure; HTN: hypertension

* patient had no encounters in the CPCSSN dataset

† RUBs estimate healthcare resource use grouped by morbidity levels: $0=$ non user to $5=$ very high morbidity

Table 2 Rates of medication coverage for patients with diabetes, for the first quarter of each year, EMR cohort

\begin{tabular}{llllllll}
\hline Drug & $2010 \mathrm{Q} 1$ & $2011 \mathrm{Q} 1$ & $2012 \mathrm{Q} 1$ & $2013 \mathrm{Q} 1$ & $2014 \mathrm{Q} 1$ & $2015 \mathrm{Q} 1$ & $2016 \mathrm{Q} 1$ \\
\hline STATIN & $62.87 \%$ & $64.71 \%$ & $64.26 \%$ & $64.82 \%$ & $63.97 \%$ & $64.01 \%$ & $65.12 \%$ \\
ACE INHIBITORS & $43.24 \%$ & $43.02 \%$ & $41.33 \%$ & $39.86 \%$ & $38.72 \%$ & $37.97 \%$ & $37.48 \%$ \\
ARB INHIBITORS & $21.07 \%$ & $21.43 \%$ & $22.25 \%$ & $22.23 \%$ & $22.62 \%$ & $22.43 \%$ & $22.87 \%$ \\
ACE or ARB & $63.40 \%$ & $63.93 \%$ & $63.10 \%$ & $61.80 \%$ & $61.20 \%$ & $60.34 \%$ & $60.36 \%$ \\
ANTIPLATELETS* & $9.39 \%$ & $8.84 \%$ & $8.48 \%$ & $7.83 \%$ & $7.39 \%$ & $6.58 \%$ & $6.49 \%$ \\
PPI & $21.85 \%$ & $23.25 \%$ & $23.79 \%$ & $24.83 \%$ & $25.36 \%$ & $27.32 \%$ & $27.65 \%$ \\
\hline
\end{tabular}

*patients with a history of myocardial infarct were excluded

ACEi: angiotensin-converting enzyme inhibitor; ARB: angiotensin receptor blockers; PPI: proton pump inhibitor 
(ODB) program. The ODB database, available at ICES, contains a copy of information on all ODB eligible medications dispensed in Ontario pharmacies including date dispensed, number of days supplied, cost and Drug Identification Number (DIN), .

Data on medications were obtained using the ODB database. We used the index date corresponding to the date when the medication was dispensed by the pharmacist.

Linked databases at ICES were used to define patient eligibility. These included claims data using the OHIP database for dates of encounters and the Registered Persons Database (RPDB) to define OHIP eligibility, basic demographics and date of death. The Client Agency Program Enrollment (CAPE) tables were used to identify enrollment with a primary care physician; for patients not enrolled, virtual enrollment to a physician was defined through their pattern of care (physician with the majority of primary care billings for a patient). The Ontario Myocardial Infarction Dataset (OMID) [22] were used to define the presence of cardiovascular conditions.

The Johns Hopkins Adjusted Clinical Groups (ACG) method was used to measure disease burden. Adjusted diagnostic groups (ADGs) cluster groups of diagnostic

Table 3 Segmented regression analysis for vascular protective medication and comparator coverage 2010 to 2016, EMR cohort

\begin{tabular}{llll}
\hline Statin & & & \\
\hline Variable & Estimate & SE & $P$ value \\
\hline Baseline prescription rate & 63.26 & 0.52 & $<.0001$ \\
Pre-intervention slope & 0.11 & 0.06 & 0.11 \\
Change at guideline (2013Q2) & -0.90 & 0.61 & 0.15 \\
Slope change & -0.03 & 0.09 & 0.70 \\
ACEi or ARB & & & \\
Baseline prescription rate & 63.99 & 0.43 & $<.0001$ \\
Pre-intervention slope & -0.15 & 0.05 & 0.01 \\
Change at guideline (2013Q2) & -0.46 & 0.51 & 0.38 \\
Slope change & 0.03 & 0.07 & 0.64 \\
Antiplatelet & & & \\
Baseline prescription rate & 9.54 & 0.15 & $<.0001$ \\
Pre-intervention slope & -0.12 & 0.02 & $<.0001$ \\
Change at guideline (2013Q2) & 0.13 & 0.17 & 0.5 \\
Slope change & 0.001 & 0.03 & 0.97 \\
PPI & & & \\
Baseline prescription rate & 21.84 & 0.44 & $<.0001$ \\
Pre-intervention slope & 0.23 & 0.05 & $<.0001$ \\
Change at guideline (2013Q2) & 0.27 & 0.43 & 0.54 \\
Slope change & -0.07 & 0.08 & 0.36 \\
\hline SE standard eror & & &
\end{tabular}

SE standard error

$A C E i$ angiotensin-converting enzyme inhibitor; $A R B$ angiotensin receptor blockers; PPI proton pump inhibitor codes (ACGs) to categorize illnesses and predict health care utilization. These diagnostic clusters, or conditions have similar clinical criteria and expected use of resources; there are 32 diagnostic clusters. Each individual patient is assigned ADGs based on their health conditions; a patient can be assigned between zero and 32 ADGs, with more ADGs indicating greater health care needs [23].

ACGs are also used to group patients by expected health care utilization, or Resource Use bands (RUBs). RUBs range from zero (non-users of health care) to five (very high users) [24].

Data from the Ontario portion of CPCSSN have been linked at ICES; linkage rates were $98.7 \%$ [21]. The population included in the linked data was slightly older, included a greater proportion of women and was more likely to live in urban areas than the Ontario population. The linked, combined data were used for this study.

\section{Quantitative variables}

An individual was considered to be covered (likely taking a medication) during a given quarter if they were found to have a supply of this medication with a duration overlapping at least $75 \%$ of days in that time period. The medication did not have to be dispensed in the given quarter, as the maximum allowed supply in ODB is 100 days. For early refills, we restricted the maximum leftover supply to be 100 days. We grouped ACEis and ARBs in the analysis as they were considered to be equivalent in terms of cardiovascular protection [25]. ARBs are often substituted if ACE is cause side effects such as coughing [25].

This study used an interrupted time series model to determine the impact of the 2013 guidelines on the prescription rates of statin, ACEi/ARB and antiplatelets on a quarterly basis from 2010 to 2016. In particular, the primary outcome included the proportion of eligible patients who had a supply of statin, ACEi/ARB or antiplatelets medication for at least 67 days (75\% of days or more) within a 90-day quarter. A total of 13 and 14 quarters were selected before and after the implementation of the Diabetes Canada guidelines in April 2013 (Quarter 2). The intervention effect is assessed using two parameters: (i) a change in trend (i.e. difference in pre-slope and post-slope) and (ii) a change in level (i.e. difference at the beginning of the intervention) [26].

Since the Diabetes Canada guidelines are readily available as a public resource to clinicians, this interrupted time series model was fitted without a roll-in period of the intervention. As part of the sensitivity analyses, the interrupted time series analysis was repeated by excluding patients with no encounters in the EMR (CPCSSN dataset), where there was therefore no opportunity to prescribe medications in primary care. 
The analyses were carried out using SAS version 9.4 (SAS Institute. SAS/STAT Software, Version 9.4. SAS, Cary, NC, 2012) and $p$-values $<0.05$ were considered to be statistically significant.

\section{Results}

\section{EMR cohort}

The size of the cohort increased from 2010 to 2015 as additional practices were being recruited each year into CPCSSN. The size of the cohort varied from 4385 patients to 7424 patients.

Patient characteristics for the first quarter of each year of interest are provided in Table 1. A table with all quarters is provided as supplementary file 1. Between 94.1 and $97.1 \%$ of patients identified using the CPCSSN algorithm were also flagged in the ODD. A greater proportion of patients in the CPCSSN data were in the highest income quintile when compared to those in the administrative data.

The rates of medications dispensed, where coverage was at least $75 \%$ of days within each quarter is shown in
Table 2. This table provides the first quarter of each year of interest and the full data are in Supplementary file 2 .

Medication coverage for patients with at least one encounter in the CPCSSN data is shown in Supplementary file 2.

Results of the interrupted time series analyses are presented in Table 3 and graphically in Fig. 1. There was no significant change in the trend for coverage of any of the vascular protective medications after guideline release. The comparator drug class, PPIs, was increasing prior to guidelines and the rate of increase did not change significantly after.

Sensitivity analyses were done, removing all patients with no encounter in the CPCSSN dataset. Results were similar and are provided in Supplementary file 3.

\section{Administrative cohort}

Patient characteristics for the first quarter of each year are provided in Table 4; all quarters are shown in Supplementary file 4. Patient characteristics were similar to those in the EMR cohort; a smaller proportion of patients were enrolled to a family physician.

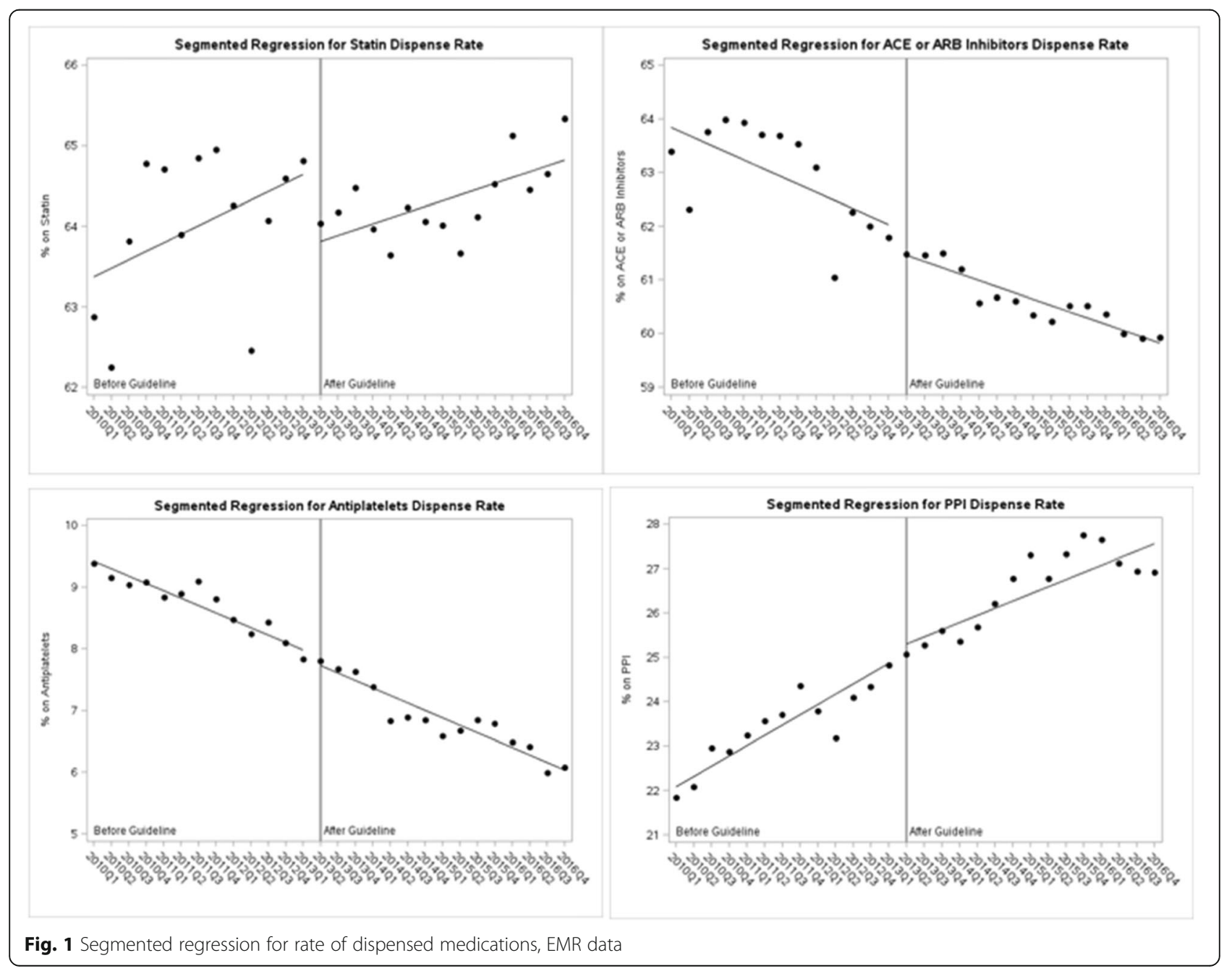


Table 4 Patient characteristics for the first quarter of each year of interest, administrative cohort

\begin{tabular}{|c|c|c|c|c|c|c|c|}
\hline & $2010 \mathrm{Q} 1$ & $2011 Q 1$ & 2012Q1 & $2013 Q 1$ & 2014Q1 & $2015 Q 1$ & 2016Q1 \\
\hline TOTAL & $N=443,608$ & $N=466,092$ & $N=488,187$ & $N=513,737$ & $N=544,224$ & $N=571,800$ & $N=599,122$ \\
\hline \multicolumn{8}{|l|}{ Age } \\
\hline Mean \pm SD & $75.60 \pm 6.84$ & $75.65 \pm 6.91$ & $75.73 \pm 6.97$ & $75.70 \pm 7.06$ & $75.66 \pm 7.15$ & $75.65 \pm 7.19$ & $75.67 \pm 7.23$ \\
\hline Median (IQR) & 75 (70-80) & 75 (70-80) & $75(70-81)$ & 75 (70-81) & $75(70-81)$ & $75(70-81)$ & $74(69-81)$ \\
\hline \multicolumn{8}{|l|}{ Sex } \\
\hline Female & $223,874(50.5 \%)$ & $234,173(50.2 \%)$ & $244,748(50.1 \%)$ & 256,606 (49.9\%) & 270,995 (49.8\%) & 284,190 (49.7\%) & 297,109 (49.6\%) \\
\hline Male & $219,734(49.5 \%)$ & $231,919(49.8 \%)$ & $243,439(49.9 \%)$ & $257,131(50.1 \%)$ & $273,229(50.2 \%)$ & $287,610(50.3 \%)$ & 302,013 (50.4\%) \\
\hline \multicolumn{8}{|l|}{ Income quintile } \\
\hline Q1 (lowest) & 95,488 (21.5\%) & 98,510 (21.1\%) & 102,097 (20.9\%) & $106,099(20.7 \%)$ & $111,256(20.4 \%)$ & 115,641 (20.2\%) & $120,280(20.1 \%)$ \\
\hline Q2 & 97,017 (21.9\%) & $101,488(21.8 \%)$ & $105,691(21.6 \%)$ & $110,832(21.6 \%)$ & 116,671 (21.4\%) & $121,898(21.3 \%)$ & $127,241(21.2 \%)$ \\
\hline Q3 & 88,583 (20.0\%) & $93,564(20.1 \%)$ & 98,297 (20.1\%) & $103,392(20.1 \%)$ & $109,813(20.2 \%)$ & $115,603(20.2 \%)$ & $121,180(20.2 \%)$ \\
\hline Q4 & 85,599 (19.3\%) & 90,808 (19.5\%) & 95,852 (19.6\%) & $101,912(19.8 \%)$ & 108,692 (20.0\%) & 115,226 (20.2\%) & 121,499 (20.3\%) \\
\hline Q5 (highest) & 75,179 (16.9\%) & 79,898 (17.1\%) & $84,350(17.3 \%)$ & 89,468 (17.4\%) & $95,666(17.6 \%)$ & 101,179 (17.7\%) & $106,523(17.8 \%)$ \\
\hline Missing & $1742(0.4 \%)$ & $1824(0.4 \%)$ & $1900(0.4 \%)$ & $2034(0.4 \%)$ & $2126(0.4 \%)$ & $2253(0.4 \%)$ & $2399(0.4 \%)$ \\
\hline Rural & $65,408(14.7 \%)$ & $68,458(14.7 \%)$ & $71,660(14.7 \%)$ & 75,092 (14.6\%) & $79,026(14.5 \%)$ & 82,247 (14.4\%) & 85,540 (14.3\%) \\
\hline \multicolumn{8}{|l|}{$A D G$} \\
\hline Mean \pm SD & $7.90 \pm 3.83$ & $7.89 \pm 3.83$ & $7.90 \pm 3.86$ & $7.89 \pm 3.88$ & $7.84 \pm 3.92$ & $7.78 \pm 3.95$ & $7.81 \pm 3.97$ \\
\hline Median (IQR) & $8(5-10)$ & $8(5-10)$ & $8(5-10)$ & $8(5-10)$ & $7(5-10)$ & $7(5-10)$ & $7(5-10)$ \\
\hline \multicolumn{8}{|l|}{$R \cup B^{*}$} \\
\hline Mean $\pm S D$ & $3.65 \pm 0.90$ & $3.65 \pm 0.90$ & $3.65 \pm 0.90$ & $3.64 \pm 0.90$ & $3.64 \pm 0.91$ & $3.64 \pm 0.91$ & $3.65 \pm 0.92$ \\
\hline Median (IQR) & $3(3-4)$ & $3(3-4)$ & $3(3-4)$ & $3(3-4)$ & $3(3-4)$ & $3(3-4)$ & $3(3-4)$ \\
\hline OMID (AMI) & $37,332(8.4 \%)$ & 39,015 (8.4\%) & $40,729(8.3 \%)$ & $42,550(8.3 \%)$ & $44,579(8.2 \%)$ & $46,463(8.1 \%)$ & $48,452(8.1 \%)$ \\
\hline \multicolumn{8}{|l|}{ Enrollment status } \\
\hline Enrolled & 374,436 (84.4\%) & $399,380(85.7 \%)$ & 424,893 (87.0\%) & $451,284(87.8 \%)$ & $482,316(88.6 \%)$ & 510,631 (89.3\%) & $538,094(89.8 \%)$ \\
\hline Virtually enrolled & $69,172(15.6 \%)$ & $66,712(14.3 \%)$ & $63,294(13.0 \%)$ & 62,453 (12.2\%) & 61,908 (11.4\%) & 61,169 (10.7\%) & $61,028(10.2 \%)$ \\
\hline CVD & 381,896 (86.1\%) & $402,524(86.4 \%)$ & 422,519 (86.5\%) & $444,766(86.6 \%)$ & 470,445 (86.4\%) & 493,342 (86.3\%) & $515,653(86.1 \%)$ \\
\hline $\mathrm{CHF}$ & 70,343 (15.9\%) & 72,678 (15.6\%) & 75,397 (15.4\%) & 78,039 (15.2\%) & 81,389 (15.0\%) & $84,822(14.8 \%)$ & 87,876 (14.7\%) \\
\hline OMID (AMI) & $37,332(8.4 \%)$ & 39,015 (8.4\%) & 40,729 (8.3\%) & $42,550(8.3 \%)$ & $44,579(8.2 \%)$ & $46,463(8.1 \%)$ & $48,452(8.1 \%)$ \\
\hline HTN & 374,702 (84.5\%) & $395,440(84.8 \%)$ & $415,646(85.1 \%)$ & $438,015(85.3 \%)$ & $463,672(85.2 \%)$ & $486,454(85.1 \%)$ & 508,602 (84.9\%) \\
\hline
\end{tabular}

ODD: Ontario Diabetes Database; SD: standard deviation; IQR: interquartile range; ADG: adjusted diagnostic groups; RUB: resource utilization band; OMID: Ontario myocardial infarct dataset; AMI: acute myocardial infarct; CVD: cardiovascular disease; CHF: congestive heart failure; HTN: hypertension

* RUBs estimate healthcare resource use grouped by morbidity levels: $0=$ non user to $5=$ very high morbidity

Table 5 Rates of medication coverage for patients with diabetes, for the first quarter of each year, 2010 to 2016, administrative cohort

\begin{tabular}{llllllll}
\hline Drug & $2010 \mathrm{Q} 1$ & $2011 \mathrm{Q} 1$ & $2012 \mathrm{Q} 1$ & $2013 \mathrm{Q} 1$ & $2014 \mathrm{Q} 1$ & $2015 \mathrm{Q} 1$ & $2016 \mathrm{Q} 1$ \\
\hline STATIN & $60.91 \%$ & $62.62 \%$ & $62.83 \%$ & $63.76 \%$ & $63.83 \%$ & $64.18 \%$ & $64.48 \%$ \\
ACEi or ARB & $61.94 \%$ & $61.80 \%$ & $60.87 \%$ & $60.72 \%$ & $60.30 \%$ & $59.72 \%$ & $59.16 \%$ \\
ANTIPLATELETS* & $10.23 \%$ & $9.97 \%$ & $9.40 \%$ & $8.79 \%$ & $8.14 \%$ & $7.48 \%$ & $6.91 \%$ \\
PPI & $22.92 \%$ & $23.91 \%$ & $24.57 \%$ & $25.56 \%$ & $26.14 \%$ & $26.72 \%$ & $27.34 \%$ \\
\hline
\end{tabular}

*patients with a history of myocardial infarct were excluded

ACEi: angiotensin-converting enzyme inhibitor; ARB: angiotensin receptor blockers; PPI: proton pump inhibitor 
The rates of medications dispensed, where coverage was at least $75 \%$ of days within each quarter is shown in Table 5. This table provides the first quarter of each year of interest and the full data are in Supplementary file 5. Rates are similar to those in the EMR cohort.

Results of the interrupted time series analyses are presented in Table 6 and graphically in Fig. 2. Similar to those in the EMR cohort, statin coverage continued to increase while ACEi/ARB coverage decreased. There was no increase in the trend for statins or ACEi/ARBs. The trend in change for antiplatelets and PPIs decreased slightly.

\section{Discussion}

This study estimated coverage for vascular protective medications in a population of Ontario patients aged 66 or more and living with diabetes. We confirmed using both a primary care EMR cohort and a population-based cohort that the release of guidelines were not associated with an increase in the rate of statin or ACEi/ARB coverage.

Our previous study evaluated the 2013 Diabetes Canada guidelines impact on vascular protective prescriptions using EMR data from CPCSSN, which had limitations in its ability to capture medication coverage, medications prescribed outside of primary care, and

Table 6 Segmented regression analysis for vascular protective and comparator medication coverage, 2010 to 2016, administrative cohort

\begin{tabular}{llll}
\hline Variable & Estimate & SE & Pvalue \\
\hline STATIN & & & \\
Baseline prescription rate & 60.99 & 0.31 & $<.0001$ \\
Pre-intervention slope & 0.20 & 0.04 & $<.0001$ \\
Change at guideline (2013Q2) & -0.26 & 0.39 & 0.51 \\
Slope change & -0.12 & 0.05 & 0.04 \\
ACEl or ARB & & & \\
Baseline prescription rate & 62.16 & 0.23 & $<.0001$ \\
Pre-intervention slope & -0.13 & 0.03 & 0.0001 \\
Change at guideline (2013Q2) & 0.21 & 0.29 & 0.46 \\
Slope change & 0.00 & 0.04 & 0.99 \\
Antiplatelet & & & \\
Baseline prescription rate & 10.46 & 0.08 & $<.0001$ \\
Pre-intervention slope & -0.12 & 0.01 & $<.0001$ \\
Change at guideline (2013Q2) & -0.09 & 0.08 & 0.29 \\
Slope change & -0.03 & 0.01 & 0.03 \\
PPI & & & \\
Baseline prescription rate & 22.67 & 0.18 & $<.0001$ \\
Pre-intervention slope & 0.22 & 0.02 & $<.0001$ \\
Change at guideline (2013Q2) & 0.09 & 0.21 & 0.67 \\
Slope change & -0.11 & 0.03 & 0.002 \\
\hline
\end{tabular}

duration of prescription given variation in refill protocols [8]. Using administrative data has helped to mitigate these concerns and validate previous findings, which revealed no increase in the rates of statin or ACEi/ARB prescriptions after guideline implementation.

Overall prescription rates from the previous study were lower (52-56\% for statins, $42-44 \%$ for ACEI/ARBs) compared to the current study (63-65\% for statins, 60 $64 \%$ for ACEI/ARB). Differences may be due to different age criteria (age $>40$ years in previous study, age $>65$ years for ODB,) or medication coverage. For example, ICES data includes an older cohort (age $>65$ years) compared to the previous study, making patients more likely to be prescribed a vascular protective medication given their age and universal prescription coverage. The difference in prescription rates was less marked for antiplatelets, which were prescribed in $10-12 \%$ of patients in our previous EMR evaluation compared to $6-10 \%$ using administrative dispensing data. We believe this difference may also be related to the increased number of over-the counter antiplatelet medications captured in CPCSSN, which are missing from ODB data.

EMR and health administrative data provide valuable tools for disease monitoring and health surveillance. With the increased use of EMR systems for clinical care, there has been a number of initiatives to link EMR data with administrative data to better identify health conditions, inform health care planning and improve patient outcomes [16, 27-29]. A number of studies demonstrate comparable data from both sources, but note differences in the way data is captured [11] [30]. [31] In terms of prescription data, the EMR contains prescriptions for patients of all ages, as well as those that are prescribed over the counter or those that are not in the provincial drug formulary. Administrative data includes drugs dispensed (rather than prescribed), and from patients who receive provincial drug coverage, often excluding those in younger age categories. Previous research suggests that approximately $14 \%$ of medications prescribed do not get filled, leading to a difference in the match rate between prescribing and dispensing data [32]. The combination of both sources thus provides a more robust understanding of medication trends in Canada.

\section{Limitations}

The CPCSSN cohort includes a convenience sample of patients who visit primary care offices, and thus findings may be limited in generalizability. Our data are also derived from the Ontario population, which may not be generalizable to other regions. Patients less than 66 years who are included in the recommendations for vascular protective medications, were not included in the current study as ICES holds medication data from patients who are 


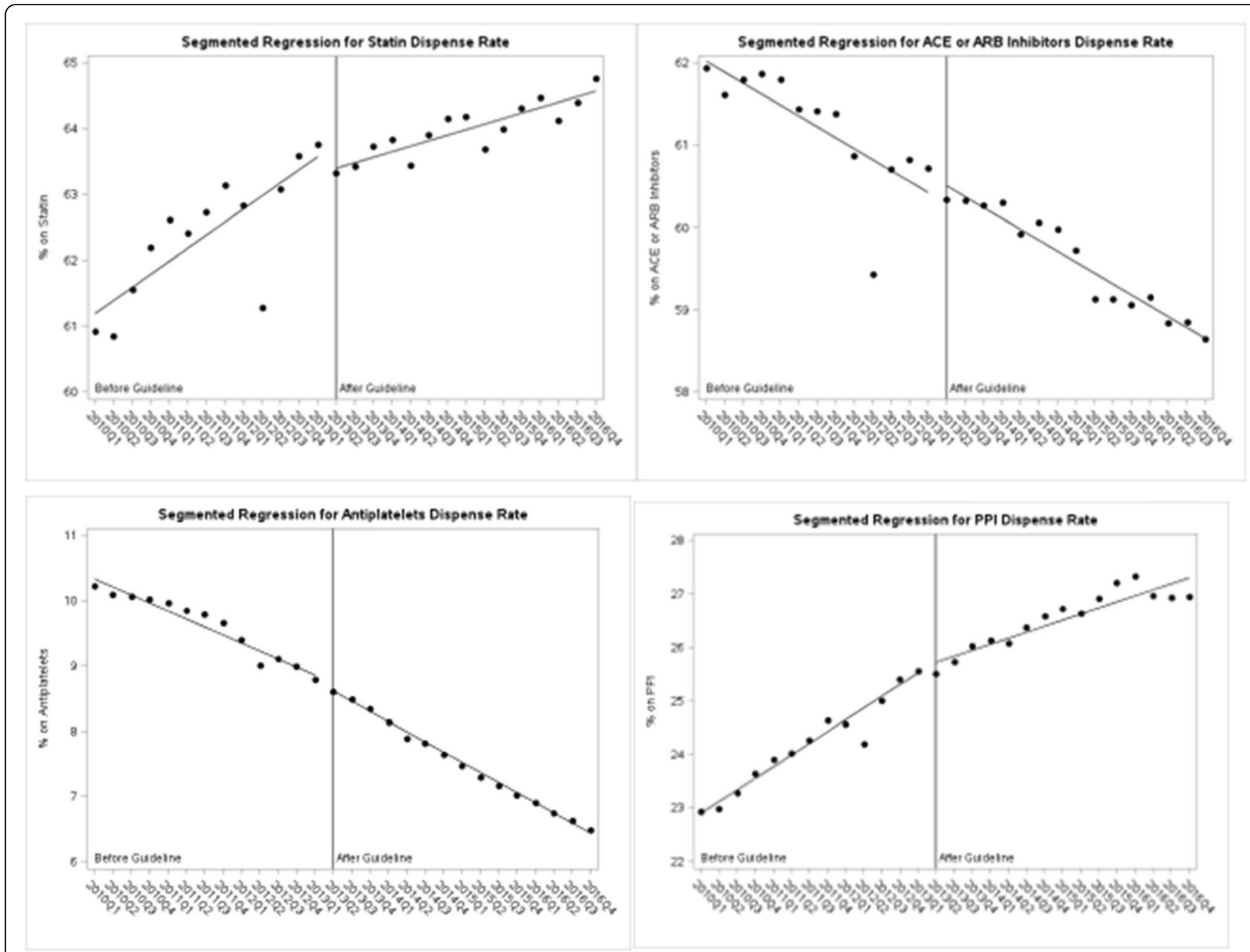

Fig. 2 Segmented regression for rate of dispensed medications, administrative data

covered through the ODB program. However, these patients were captured in our previous assessment and demonstrated similar medication trends. This also means that patients without OHIP coverage and those with over the counter prescriptions would not have been captured, however we expect these would represent a small minority of patients overall. Finally, results must be interpreted with caution as administrative data capture medications dispensed, and actual usage of the medications was inferred from these estimates.

\section{Conclusions}

The use of both EMR and administrative data provides a more comprehensive picture of the current state of vascular protection for patients with diabetes in Ontario, Canada. This research helps validate previous findings, which used EMR data and found no improvement in vascular protective prescription rates following the 2013 Diabetes Canada Guidelines implementation and dissemination. Given the similarity in findings between EMR and administrative data, our results suggest that
EMR data may offer an additional tool to understand prescription trends across Canada with reasonable accuracy. Future work will be directed at validating the methodology used in analyzing such data, including the lag lead approach from our previous study. Further research efforts are also needed to examine reasons for ongoing vascular protection guideline non-adherence in primary care, including more qualitative assessments.

\section{Supplementary information}

Supplementary information accompanies this paper at https://doi.org/10. 1186/s12913-020-05232-3.

Additional file 1. Supplementary file 1. Patient characteristics for all quarters of each year of interest, EMR cohort.

Additional file 2. Supplementary file 2: Rates of medication coverage for patients with diabetes, for all quarters of each year, EMR cohort.

Additional file 3. Supplementary file 3. Segmented regression analysis for vascular protective medication and comparator coverage, 2010 to 2016, EMR cohort, for patients with at least one encounter.

Additional file 4. Supplementary file 4. Patient characteristics for all quarters of interest, administrative cohort. 
Additional file 5. Supplementary file 5. Rates of medication coverage for patients with diabetes, for all quarters, 2010 to 2016, administrative cohort.

\section{Abbreviations}

ACEi: Angiotensin-converting enzyme inhibitor; ARB: Angiotensin receptor blocker; CPCSSN: Canadian Primary Care Sentinel Surveillance Network; EMR: Electronic medical record; ICES: Institute for Clinical Evaluative Sciences; ODD: Ontario Diabetes Database; OHIP: Ontario Health Insurance Plan; PPI: Proton pump inhibitor

\section{Acknowledgements}

We are grateful to the physicians and patients who allow data sharing for networks participating in CPCSSN. This work was presented at the 2019 Diabetes Canada conference in Winnipeg, Manitoba, October 3; the abstract was published in the Canadian Journal of Diabetes (https://doi.org/10.1016/ j.jcjd.2019.07.122). Parts of this material are based on data and/or information compiled and provided by $\mathrm{ClHI}$. However, the analyses, conclusions, opinions and statements expressed in the material are those of the author(s), and not necessarily those of $\mathrm{CIHI}$. We thank IMS Brogan Inc. for use of their Drug Information Database.

\section{Authors' contributions}

MG and SK conceptualized the study with contributions from all authors; MG wrote the first draft of the manuscript, with contributions from AR, SK, SC, RD and RM. SK and SC analyzed the data and presented the results, which were reviewed by RM, SK and MG, and interpreted by all authors. All authors reviewed and revised the article for important intellectual content and gave final approval of the version to be published. MG is the guarantor of this paper and had final responsibility for the decision to submit for publication.

\section{Funding}

This study was supported by Diabetes Action Canada which is funded, in part, through a Canadian Institutes of Health Research chronic disease network grant under the Strategy for Patient-Oriented Research (Funding Reference number: SCA 145101) by patient-oriented research support funding from the Ontario SPOR SUPPORT Unit through its Research Centre at the Institute for Clinical Evaluative Sciences and by the Institute for Clinical Evaluative Sciences (ICES), which is funded by an annual grant from the Ontario Ministry of Health and Long-Term Care (MOHLTC). Dr. Greiver is supported through the Gordon F. Cheesbrough Research Chair in Family and Community Medicine from North York General Hospital. The Canadian Primary Care Sentinel Surveillance Network was a committee of the College of Family Phy sicians of Canada and was funded through a contribution agreement with the Public Health Agency of Canada. The opinions, results and conclusions reported in this paper are those of the authors and are independent from the funding sources. No endorsement by ICES, CPCSSN or the MOHLTC is intended or should be inferred.

\section{Availability of data and materials}

The dataset from this study is held securely in coded form at the Institute for Clinical Evaluative Sciences (ICES). While data sharing agreements prohibit ICES from making the dataset publicly available, access may be granted to those who meet pre-specified criteria for confidential access, available at https://www.ices.on.ca/DAS. The full dataset creation plan and underlying analytic code are available from the authors upon request, understanding that the programs may rely upon coding templates or macros that are unique to ICES. The corresponding author should be contacted for the dataset creation plan.

\section{Ethics approval and consent to participate}

The study protocol was approved by the Research Ethics Board at Sunnybrook Health Sciences Center, Toronto, ON, Canada. We received administrative permission from ICES for the analysis. ICES is a prescribed entity under section 45 of Ontario's Personal Health Information Protection Act. Section 45 authorizes ICES to collect personal health information without consent, for the purposes of analysis and compiling statistical information about the health system.

\section{Consent for publication}

Not applicable.

\section{Competing interests}

The authors declare that they have no competing interests.

\section{Author details}

${ }^{1}$ Gordon F. Cheesbrough Chair in Family and Community Medicine Research, North York General Hospital, 4001 Leslie Street, LE-140, Toronto, Ontario M2K 1E1, Canada. ${ }^{2}$ Department of Family and Community Medicine, Faculty of Medicine, University of Toronto, 500 University Avenue, Toronto, Ontario M5G 1V7, Canada. ${ }^{3}$ ICES, G1 06, 2075 Bayview Avenue, Toronto, Ontario M4N 3M5, Canada. ${ }^{4}$ Institute of Health Policy, Management and Evaluation, University of Toronto, Toronto, Canada. ${ }^{5}$ Faculty of Medicine, University of Toronto, 1 King's College Cir, Toronto, Ontario M5S 1A8, Canada.

Received: 5 June 2019 Accepted: 15 April 2020

Published online: 01 May 2020

\section{References}

1. Kannel WB, McGee DL. Diabetes and cardiovascular disease. The Framingham study JAMA. 1979;241(19):2035-8.

2. Stone JA, Fitchett D, Grover S, Lewanczuk R, Lin P, Committee CDACPGE. Vascular protection in people with diabetes. Can J Diabetes. 2013;37(Suppl 1):S100-4.

3. Bhattacharyya OK, Estey EA, Cheng AYY. Update on the Canadian Diabetes Association 2008 clinical practice guidelines. Can Fam Physician. 2009;55(1): 39.

4. Straus S, Tetroe J, Graham I. Knowledge translation in health care: moving from evidence to practice. Wiley, editor2011.

5. Yu CH, Lillie E, Mascarenhas-Johnson A, Gall Casey C, Straus SE. Impact of the Canadian Diabetes Association quideline dissemination strategy on clinician knowledge and behaviour change outcomes. Diabetes Res Clin Pract. 2018:140:314-23.

6. Stone JA, Houlden RL, Lin P, Udell JA, Verma S. Cardiovascular protection in people with diabetes. Can J Diabetes. 2018:42:S162-S9.

7. Birtwhistle R, Keshavjee K, Lambert-Lanning A, Godwin M, Greiver M, Manca D, et al. Building a pan-Canadian primary care sentinel surveillance network: initial development and moving forward. J Am Board Fam Med. 2009;22(4):412-22.

8. Rigobon AV, Kalia S, Nichols J, Aliarzadeh B, Greiver M, Moineddin R, et al. Impact of the Diabetes Canada Guideline Dissemination Strategy on the Prescription of Vascular Protective Medications: A Retrospective Cohort Study, 2010-2015. Diabetes Care 2018

9. Greiver M, Barnsley J, Glazier RH, Harvey BJ, Moineddin R. Measuring data reliability for preventive services in electronic medical records. BMC Health Serv Res. 2012;12:116.

10. Cadarette SM, Wong L. An introduction to health care administrative data. The Canadian journal of hospital pharmacy. 2015;68(3):232-7.

11. Tu K, Mitiku TF, Ivers NM, Guo H, Lu H, Jaakkimainen L, et al. Evaluation of electronic medical record administrative data linked database (EMRALD). Am J Manag Care. 2014;20(1):e15-21.

12. Williamson T, Green ME, Birtwhistle R, Khan S, Garies S, Wong ST, et al. Validating the 8 CPCSSN case definitions for chronic disease surveillance in a primary care database of electronic health records. The Annals of Family Medicine. 2014;12(4):367-72.

13. Tu K, Manuel D, Lam K, Kavanagh D, Mitiku TF, Guo H. Diabetics can be identified in an electronic medical record using laboratory tests and prescriptions. J Clin Epidemiol. 2010.

14. Hux JE, Ivis F, Flintoft V, Bica A. Diabetes in Ontario: determination of prevalence and incidence using a validated administrative data algorithm. Diabetes Care. 2002:25(3):512-6.

15. Greiver M, Williamson T, Barber D, Birtwhistle R, Aliarzadeh B, Khan S, et al. Prevalence and epidemiology of diabetes in Canadian primary care practices: a report from the Canadian primary care sentinel surveillance network. Can J Diabetes. 2014;38(3):179-85.

16. Lipscombe LL, Hwee J, Webster L, Shah BR, Booth GL, Tu K. Identifying diabetes cases from administrative data: a population-based validation study. BMC health services research. 2018;18(1):316-

17. Ishiguro L, Saskin R, Vermeulen MJ, Yates E, Gunraj N, Victor JC. Increasing access to health administrative data with ICES Data \& Analytic Services. Healthc Q. 2016;19(1):7-9. 
18. von Elm E, Altman DG, Egger M, Pocock SJ, Gotzsche PC, Vandenbroucke $J$, et al. The strengthening the reporting of observational studies in epidemiology (STROBE) statement: guidelines for reporting observational studies. Int J Surg. 2014;12(12):1495-9.

19. Marchildon GP, Hutchison B. Primary care in Ontario, Canada: new proposals after 15 years of reform. Health Policy. 2016;120(7):732-8.

20. Williamson T, Birtwhistle R, Green M, Khan S, Wong S, Natarajan N, et al. Validating the CPCSSN algorithms for eight chronic conditions. Family Medicine Forum; Vancouver2013.

21. Birtwhistle R, Green ME, Frymire E, Dahrouge S, Whitehead M, Khan S, et al. Hospital admission rates and emergency department use in relation to glycated hemoglobin in people with diabetes mellitus: a linkage study using electronic medical record and administrative data in Ontario. CMAJ Open. 2017;5(3):E557-e64.

22. Tu JV, Austin PC, Walld R, Roos L, Agras J, McDonald KM. Development and validation of the Ontario acute myocardial infarction mortality prediction rules. J Am Coll Cardiol. 2001;37(4):992-7.

23. Austin PC, van Walraven C, Wodchis WP, Newman A, Anderson GM. Using the Johns Hopkins aggregated diagnosis groups (ADGs) to predict mortality in a general adult population cohort in Ontario. Canada Medical care. 2011; 49(10):932-9.

24. Glazier R, Zagorski B, Rayner J. Comparison of Primary Care Models in Ontario by Demographics, Case Mix and Emergency Department Use, 2008/ 09 to 2009/10. ICES investigative report. Toronto, Ontario: Institute for Clinical Evaluative Sciences; 2012.

25. Canadian Diabetes Association Clinical Practice Guidelines Expert Committee. Canadian Diabetes Association 2013 Clinical Practice Guidelines for the Prevention and Management of Diabetes in Canada. Can J Diabetes. 2013;37(supple 1):S1-S212.

26. Wagner AK, Soumerai SB, Zhang F, Ross-Degnan D. Segmented regression analysis of interrupted time series studies in medication use research. J Clin Pharm Ther. 2002;27(4):299-309.

27. The value of Ontario's electronic health data infrastructure; a brief report from the perspective of the Institute for Clinical Evaluative Sciences. Toronto, Ontario, Canada: Institute for Clinical Evaluative Sciences; 2016.

28. Hux J, Booth G, Slaughter P, Laupacis A. Diabetes in Ontario: an ICES practice atlas. Toronto; 2003

29. Harris SB, Glazier RH, Tompkins JW, Wilton AS, Chevendra V, Stewart MA, et al. Investigating concordance in diabetes diagnosis between primary care charts (electronic medical records) and health administrative data: a retrospective cohort study. BMC Health Serv Res. 2010;10:347.

30. Devoe JE, Gold R, McIntire P, Puro J, Chauvie S, Gallia CA. Electronic health records vs Medicaid claims: completeness of diabetes preventive care data in community health centers. Ann Fam Med. 2011;9(4):351-8.

31. Tang PC, Ralston M, Arrigotti MF, Qureshi L, Graham J. Comparison of methodologies for calculating quality measures based on administrative data versus clinical data from an electronic health record system: implications for performance measures. J Am Med Inform Assoc. 2007;14(1): $10-5$.

32. Gardner TL, Dovey SM, Tilyard MW, Gurr E. Differences between prescribed and dispensed medications. N Z Med J. 1996;109(1017):69-72.

\section{Publisher's Note}

Springer Nature remains neutral with regard to jurisdictional claims in published maps and institutional affiliations.

Ready to submit your research? Choose BMC and benefit from:

- fast, convenient online submission

- thorough peer review by experienced researchers in your field

- rapid publication on acceptance

- support for research data, including large and complex data types

- gold Open Access which fosters wider collaboration and increased citations

- maximum visibility for your research: over $100 \mathrm{M}$ website views per year

At BMC, research is always in progress.

Learn more biomedcentral.com/submissions 